Nevşehir Bilim ve Teknoloji Dergisi Cilt 6(ICAFOF 2017 Özel Sayı) 271-279 2017

DOI: 10.17100/nevbiltek.322983

URL: http://dx.doi.org/10.17100/nevbiltek.322983

\title{
Antalya İlinin Organik Bitkisel Üretim Potansiyelinin Dünya ve Türkiye ile Kıyaslanması ve Gelişmesine Yönelik Öneriler
}

\author{
Kamile Ulukapı, Sevinç Şener ${ }^{*}$ \\ Akdeniz Üniversitesi, Teknik Bilimler Meslek Yüksekokulu, Bitkisel ve Hayvansal Üretim Bölümü, \\ Organik Tarım Programi, Antalya
}

Öz

Genel olarak Akdeniz iklimine sahip olan Antalya ili zengin tür çeşitliliğine sahiptir. Antalya ilindeki tarım alanları ve bitkisel üretim değerleri Türkiye geneli içerisinde önemli bir yer tutmaktadır. Topografik yapısı ve iklim özellikleri sebebiyle organik bitkisel üretim açısından avantajlara sahip olan ilde, organik bitkisel üretim konvansiyonel üretim ile rekabet edememekte ve organik bitkisel üretim rakamlarının hayli düşük olduğu görülmektedir. Bu derlemede, öncelikle Dünya'da ve Türkiye'de yapılan organik bitkisel üretim irdelenmiş, Antalya ilinin mevcut durumu ve potansiyeli ortaya konulmuş, üretimin arttrrılması için çözüm önerileri sunulmuştur.

Anahtar Kelimeler: Antalya, Organik Ürün, Sürdürülebilirlik, Tarım

\section{The Comparison of Organic Plant Production Potential in the Province of Antalya with Turkey and the World, and Some Suggestions on the Development of This \\ Potential}

\begin{abstract}
Being situated in the zone of Mediterranean climate, Antalya has a wide range of bio-diversity. The agricultural fields and plant production values have reserved a significant place when to be compared with the general values of Turkey. Though Antalya bears some advantages in terms of organic plant production because of its topographic structure and climatic characteristics, it is easily observed that the organic plant production in Antalya cannot compete with the conventional production, and that the figures of organic plant production are too low. Throughout this review, the organic plant production in Turkey and the whole world has been firstly examined, and then the current situation and potential of Antalya has been covered, and some suggestions of solution have been presented accordingly.
\end{abstract}

Keywords: Antalya, Organic Product, Sustainability, Agriculture

* e-mail: ssener@akdeniz.edu.tr 
Ulukapı K., Şener S.

\section{Giriş}

İnsanoğlu var olduğu günden itibaren beslenme ihtiyacı duymuştur. Avcılık ve toplayıcıllk döneminden sonra ortaya çıkan tarımsal üretim sistemleri tarih boyunca gelişmeler göstermiştir. II. Dünya savaşı sonrasında artan dünya nüfusunun gıda ihtiyacının karşılanmasında, mevcut tarımsal üretim sistemleri yetersiz kalmıştır. 1950'lerden itibaren ise tarımsal üretimde verimi artırmak amacıyla teknolojinin, mekanizasyonun ve sentetik kimyasalların kullanımı önemli bir artış göstermiştir. Teknolojinin ve sentetik kimyasalların yoğun olarak kullanıldığı Modern Tarım, Yeşil Devrim ve Konvansiyonel Tarım gibi üretim sistemleri bazı çevre ve sağlık problemlerine sebep olmuştur. Yoğun sentetik kimyasal girdi ve mekanizasyonun kullanıldığı tarımsal üretim sistemleri tarımın, ekolojik, ekonomik ve sosyal kıstaslarla bir örüntü içerisinde olduğunu göz ardı etmiş, kısa vadede yüksek verim elde etmeye odaklanmışlardır [1]. Bu üretim modellerinde sentetik kimyasallar, kolay uygulanabilirliği ve hızlı sonuç vermeleri sebebiyle vazgeçilmez maddeler olarak kabul edilmiştir. Fakat bu maddelerin bilinçsiz ve kontrolsüz uygulanmaları insan, hayvan ve çevre sağlı̆̆ını tehdit etmekte, hava, su, toprak ve yaban hayatını olumsuz etkilemekte, gıda ürünlerinde kalıntılar oluşturmakta, hedef alınan zararlılarda dayanıklılık oluşturmakta, önemli olmayan bazı zararlıları ana zararlı konumuna geçirmekte ve bitkilerde fitotoksititeye sebep olmaktadır [2].

Dünyada ve ülkemizde hastalık ve zararlıları yok etmek ve kaliteli ürünler elde etmek amacıyla kullanılmakta olan pestisitler, hedef organizmaları yok ettiği gibi hedef dışı canlılara da zarar verebilmektedir [3]. Dünya Sağlık Örgütü (WHO) verilerine göre; her yıl 3 milyon tarım işçisi pestisitlerden zehirlenmekte ve bunların 18 bini ölmektedir. Ayrıca yapılan çalışmalarda uzun süre pestisitlerle çalışan kişilerde, solunum problemleri, hafıza zayıflığı, dermatolojik sorunlar, kanser, depresyon, nörolojik hasarlar, çocuk düşürme gibi problemlerin görüldüğü tespit edilmiştir [4]. Ortaya çıkan bu tablodan hem üreticiler hem de tüketiciler olumsuz etkilenmiştir. Tarım bilimciler ise tüm bu olumsuz etkiler nedeniyle tarımın sürdürülebilirliğinden endişe duymaya başlamış ve alternatif tarım modellerini ortaya koymuşlardır. Bitkisel ve hayvansal üretimin birlikte yürütüldüğü, üretim ve tüketim arasındaki zincirin daha kısa olduğu tarım modellerinin sürdürülebilirlik açısından daha avantajı olduğu bilinmektedir.

Organik tarım sürdürülebilir bir tarımsal üretim modeli olup, ekosistemi ve insan sağlığını korumaktadır. Organik tarımda toprak verimliliğini arttırmak veya hastalık ve zararlı etmenlerle mücadele etmek için ekim nöbeti, yeşil gübreleme, kompost uygulaması ve biyolojik mücadele gibi teknikler kullanılmaktadır. Organik tarım, eski ve yenilikçi uygulamaları birleştirmekte, tüm canlıların ortak yaşadığı çevreyi korumakta ve içerdiği prosesler gereğince canlılar arasındaki ilişkileri kuvvetlendirmektedir. Diğer tarımsal üretim modellerine göre, izlenebilirliği ve güvenilirliği yüksek olan bir sistemdir; ürünün üretim aşamasından tüketiciye ulaşmasına kadar olan işlemleri kontrol ve sertifikasyon kuruluşları tarafından kayıt altına alınarak izlenmekte ve denetlenmektedir [5].

Bu çalışma ile tarım sektöründe önemli bir yeri olan Antalya ilinin organik tarım potansiyelini, mevcut durumunu ortaya koymak ve ülke ekonomisine olan katkısını değerlendirmek amaçlanmıştır. Ayrıca çalışmada Antalya ilinin organik tarım potansiyelinin daha verimli kullanılmasını sınırlayan faktörler tartışılarak öneriler ortaya konulmuştur. 


\section{Organik Tarımın Dünya'da ve Türkiye'deki Durumu}

Organik tarıma ilişkin veriler 1972 yılında Almanya'da kurulan, IFOAM (Uluslararası Ekolojik Tarım Hareketleri Federasyonu) isimli kuruluştan elde edilebilmektedir. IFOAM'in organik üreticileri örgütleyerek oluşturduğu "Organik Tarım ve Gıda İşletmesine İlişkin Uluslararası Temel Standartlar" sertifikasyon programları için bir çerçeve oluşturmaktadır [6].

FIBL ve IFOAM' in 2014 yılı raporuna göre; 164 ülkede, 1.9 milyon sertifikalı organik üretici, 37.5 milyon hektar alanda organik tarımsal üretim gerçekleştirmektedir. 2013 yılının değerlerini içeren bu veriler, 2007 yılı verileri ile kıyaslandığında 6 yıllık bir süreçte, organik tarım yapan ülke sayısının 141'den 164'e, 35 milyon ha'lık alanın ise 37.5 milyon ha'a ulaştığı görülmektedir.

Organik tarım alanlarının kıtalara göre dağılımı incelendiğinde ilk sırada Okyanusya'nın (12.2 milyon ha) olduğu görülmektedir (Şekil1). En fazla organik tarım alanına sahip olan ilk üç ülke ise sırasiyla; Avustralya (12 milyon ha), Arjantin (3.8 milyon ha) ve ABD (1.9 milyon) olarak bildirilmektedir.

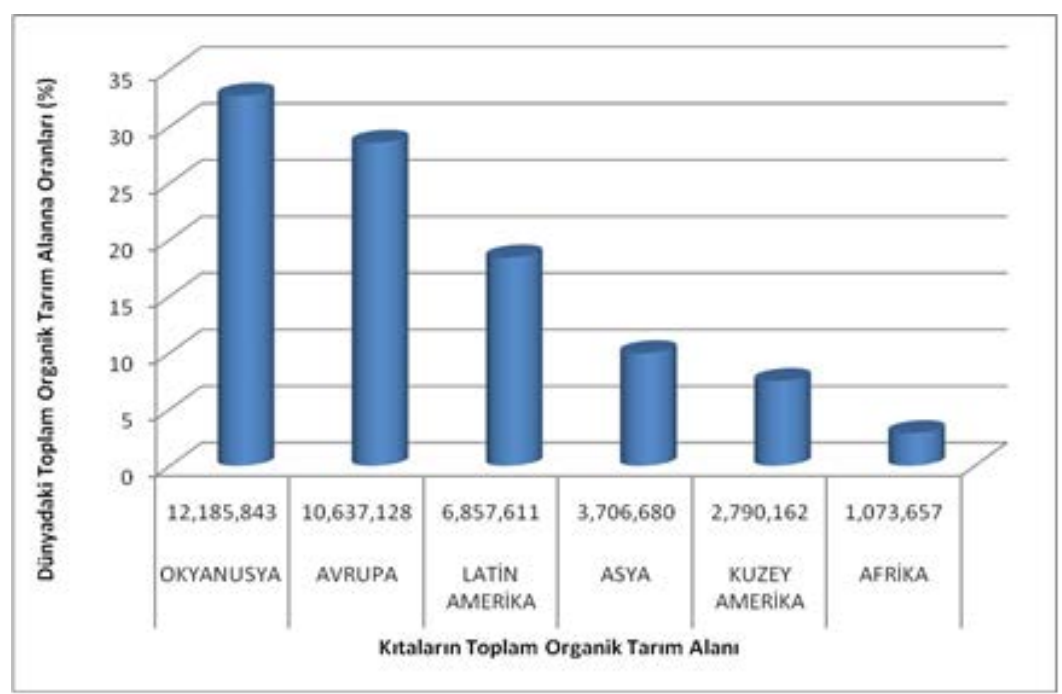

Şekil 1. Kıtaların organik tarım alanları ve bu alanların dünya toplam organik tarım alanına oranı[7]

Dünyada organik tarım alanlarının \%66'sı otlak ve otlatma alanı, \%17'si ekilebilir alan, \%7'si ise çok yıllık bitki yetiştiriciliği alanı olarak değerlendirilmektedir. Şekil 2'de yer alan ekilebilir alanlardaki ürün dağıllımı incelendiğinde, birinci sırada (çeltik yetiştiriciliğinin de dahil olduğu) tahıllar (2.6 milyon ha) yer almakta, bunu yeşil yem (2.2 milyon ha), yağlı tohumlar (0.5 milyon ha) izlemekte, en düşük oranın ise sebze yetiştiriciliğinde ( 0.2 milyon ha) olduğu görülmektedir.

Organik olarak yetiştirilen çok yıllık bitkiler, 2.6 milyon ha'lık bir alanı kaplamaktadır. Çok yıllık yetiştiricilik yapılan alanların önemli bir bölümünde kahve ( 0.6 milyon ha), zeytin ( 0.5 milyon ha), findık (0.3 milyon ha) ve kakao (0.2 milyon ha) yetiştirilmektedir. Bunların dışında organik olarak üretilen diğer bazı ürünler ise şu şekilde sıralanabilmektedir; üzüm (284 bin ha), tropikal ve subtropikal meyveler (218 bin ha), 1lıman iklim meyveleri (164 bin ha) ve üzümsü meyveler (42.6 bin ha).

Tüm dünyada organik ürünlerin pazar değeri 63.8 milyar dolar civarındadır. Pazarın 29 milyar dolarlık kısmının ABD’ye, 9.2 milyar dolarlık kısmının Almanya'ya, 5.2 milyar dolarlık kısmının da 
Fransa'ya ait olduğu belirtilmektedir. Dünyadaki organik tarım alanlarının \%1.2'sine sahip olan Türkiye’nin ise pazardaki payının 300-350 milyon dolar olduğu bildirilmektedir [8] .

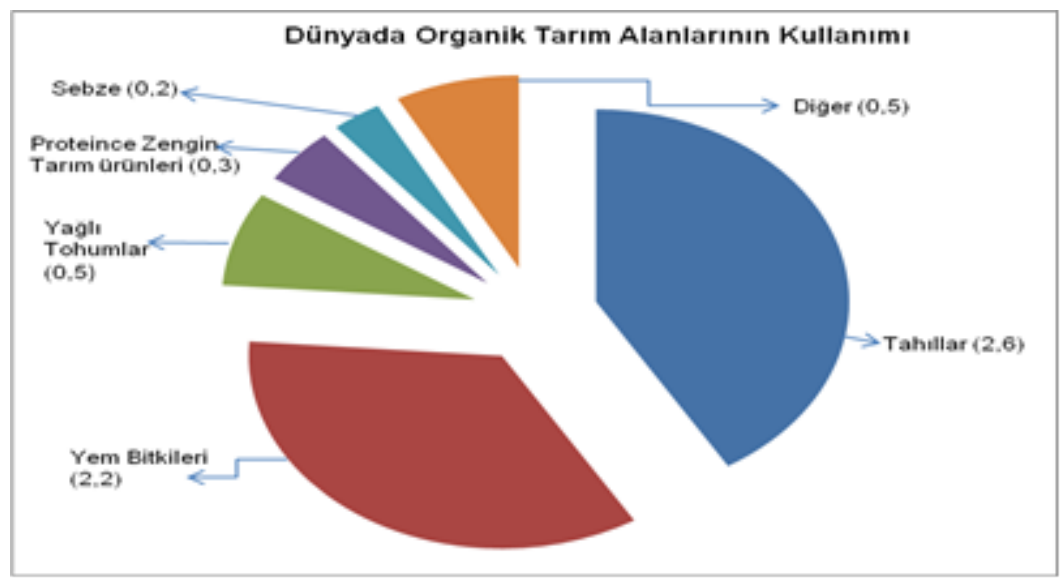

Şekil 2. Dünya organik ekilebilir tarım alanlarındaki ürün deseni (milyon ha) [7]

Gelişmekte olan ülkelerde organik tarım genellikle Avrupa'dan gelen talep sonrası başlamaktadır [9]. Türkiye'de organik tarım, 1984-85 yıllarında kuru üzüm ve kuru incir ihracatı ile başlamış [10], 2000'li yıllarda ürün çeşitliliği giderek artış göstermiştir. Tarım ve Köyişleri Bakanlığı tarafından 22145 sayılı 'Bitkisel ve Hayvansal Ürünlerin Ekolojik Üretilmesine İlişkin Yönetmelik' 18 Aralık 1994 tarihinde yürürlüğe girdikten sonra, toplam organik üretim alanı, organik üretici sayısı ve ürün çeşitliliğinde artışlar gözlenmiştir [11].

2002 yılında “Organik Tarımın Esasları ve Uygulanmasına İlişkin Yönetmelik” yayınlanmış, sonrasında ise organik ürünlerin üretimi, tüketimi ve denetlenmesine dair bir kanun tasarısı 03 Aralık 2004 tarihli ve 25659 sayılı Resmi Gazete'de yayımlanarak yürürlüğe girmiştir. Kanun ile organik tarımsal faaliyetler, kontrol ve sertifikasyon hizmetleri yasal dayanağa kavuşturulmuş, kuralları ihlal edenlere cezai hükümler getirilmiş, ulusal ve yerel radyo ile televizyonların organik tarımla ilgili yayın yapmaları sağlanmıştır. Bu Kanun'a dayalı olarak hazırlanan “Organik Tarımın Esasları ve Uygulanmasına İlişkin Yönetmelik” ise, 2005 yılında yürürlüğe girmiştir. Avrupa Birliği’nin 2092/91 sayılı Konsey Tüzüğünün yerine, 834/2007 sayılı Konsey Tüzüğü ve 889/2008 sayılı Komisyon Tüzüğünün 1 Ocak 2009 yılında yürürlüğe girmesi sonucunda, ulusal organik tarım mevzuatı AB Mevzuatı ile uyumlu hale getirilmiş ve 2010 yılında yeniden yayımlanmıştır [12].

Türkiye'nin organik bitkisel üretim potansiyeli değerlendirildiğinde; 2013 yılı itibarı ile 213 çeşit üründe, 769.014 ha alanda, 60.797 adet üreticinin, 1.620 .466 ton organik üretimin gerçekleştirildiği görülmektedir [13]. Bununla birlikte, Türkiye'nin organik tarım alanlarının yaklaşık olarak 172 bin ha'lık kısmını doğadan toplama alanları oluşturmaktadır. Doğadan toplama alanlarına bakıldığında 338 bin ha' lık alandan meyvelerin, 165 bin ha'lık bir alandan tıbbi ve aromatik bitkilerin, 54 bin ha'lık alandan ise üzümsü meyvelerin toplandığı bildirilmektedir [14].

Ekilebilir alanların 210 bin ha'lık kısmında tahıl üretimi yapılmaktadır. Çok yıllık bitkilerde ise 32 bin ha'lık bir alanla zeytin ön plandadır. Türkiye dünyanın en büyük beşinci organik 1lıman iklim meyve üreticisidir ve organik ılıman iklim meyveleri yetiştiriciliği 11 bin ha’lık alanda yapılmaktadır [14]. 
Türkiye'de başlangıçta ihracat istekleri doğrultusunda üretilen organik ürünlere artık yurt içinden de talepler gelmekte ve bu talepler doğrultusunda; reçel, marmelat, ayçiçeği yağı, balmumu, çikolata, kahve, soya unu ve zencefilli kurabiye gibi çeşitli organik ürünlerin ithalatı da yapılmaktadır. Türkiye, 2011 yılında 18 ülkeden organik ürün ithal edilmiştir [12].

AB ülkeleri ile kıyaslandığında, Türkiye'de organik ürünlerinin tüketimi daha düşük seviyelerdedir. Bu durum organik ürünlerin fiyatının yüksekliği ve tüketicilerin yetersiz bilgiye sahip olmaları ile ilişkilendirilebilmektedir [15].

\section{Antalya İlinin Tarımsal Yapısı ve Organik Tarım Potansiyeli}

Antalya ili, Türkiye'nin güneyinde, merkezi Akdeniz kıyısında 30o 42' E enleminde ve 36o 53' N boylamında yer almaktadır. Kuzeyinde; Burdur, Isparta, Konya, doğusunda; Karaman, Mersin, batısında; Muğla illeri vardır. Güneyi, Akdeniz ile çevrelenmiştir. Yüzölçümü $20.723 \mathrm{~km}^{2}$ olup nüfusu 2.043.4822'dir. İklimi genel olarak Akdeniz iklimine girmekte, iç kesimlerde ise "Soğuk Yarı-Kara İklim" tipi görülmektedir. Topoğrafik yapısı, coğrafi konumu ve iklim koşulları nedenleriyle zengin bir bitki örtüsüne sahiptir. Batı Akdeniz Bölgesi’nde bulunan 750 endemik türün 500 tanesi Antalya'da yayılış göstermektedir. Bu türlerden 200 tanesi ise, Antalya' ya özgü endemik tür olarak kayıtlara girmiştir. Antalya bu açıdan ülkemizin en çok endemik bitki türüne sahip ili olma özelliğini taşımaktadır [16].

Antalya ilinde 293.408 ha işlenen tarım alanı bulunmaktadır. Bunun 245.94 ha'lık kısmında tahıllar ve diğer bazı bitkisel ürünler, 46.91 ha'da sebze, 52.42 ha'da meyve ve baharat bitkileri, 16.53 ha'da ise zeytin yetiştiriciliği yapılmaktadır [13].

TÜIK'den alınan 2013 yılı verilerine göre, Antalya'nın mevcut tarımsal yapısı irdelendiğinde; tarım alanlarının \%75'lik kısmında tahılların bulunduğu görülmektedir. Patates, kuru baklagiller, yenilebilir kök ve yumrular ise \%12'lik pay ile ikinci sırada yer almaktadır. Üretim değerlerine göre yapılan değerlendirmede ise; Türkiye sebze üretimi içinde Antalya'nın sebze üretim payının \%14.1, meyve üretim payının ise \%6.6 olduğu bildirilmektedir. Antalya ilinin sebze ve meyve üretimindeki en büyük oranın \%66.7 ile domatese (2.134.374 ton) ait olduğu, bunu \%14.19 ile hiyar (453.928 ton) ve \% 8.03 ile biberin (257.151 ton) izlediği bildirilmektedir [17].

Yüksek bir bitkisel üretim potansiyeline sahip olan ilde sürdürülebilirliğin yoğun tarımsal uygulamalar (zirai ilaçlama, sulama, gübreleme, mekanizasyon) nedeniyle çıkmaza girdiği söylenebilir. Kaplan ve ark. [18] Antalya bölgesinde bulunan kuyu sularının \%50'sinin nitrat içeriğinin $165 \mathrm{mg}$ NO3/L'nin üzerinde olduğunu ve bu oranın Dünya Sağlık Örgütü (WHO) sınırının (45 mg NO3/L) 3 katından daha fazla olduğunu bildirmektedirler. Nitekim, Türkiye'nin yaş meyve ve sebze ihtiyacının önemli bir kısmını tedarik eden ilde Türkiye toplam pestisit kullanımının \%7.4'ünün gerçekleştiği de bildirilmektedir [19].

Delen'e göre Antalya, Adana, Mersin ve İzmir entansif tarım yapılan illerdir ve bu bölgelerdeki pestisit kullanımı ülke ortalamasının çok üzerindedir [20]. İhracata yönelik meyve sebze tedarikinin yapıldığı bu bölgelerdeki yoğun pestisit kullanımı ise bitkisel üretim açısından önemli bir sorun olarak karşımıza çıkmaktadır. Atılgan ve ark. yaptıkları çalışmada Antalya ilinde bitkisel üretim yapan 
üreticilerin verim dışındaki kriterlere önem vermediklerini, çevresel problemlerini ise hiç dikkate almadıklarını bildirmiş ve bu durumun eğitimle ilişkili olduğunu belirtmişlerdir [21].

Tarımsal sürdürülebilirliğin sağlanması için, tarımsal ürünlerin ve tarımsal girdilerin, çevre ve insan sağlığını koruyarak, kaliteli ve düşük maliyetle üretilmesi gerekmektedir. Bu noktada "Organik Tarım" metodu bir alternatif olarak karşımıza çıkmaktadır.

Antalya ilinin organik bitkisel üretim verileri incelendiğinde ise; hali hazırda, 39 adet üreticinin, 12.421.07 ha'lık alanda, 3.188.01 ton organik üretim yaptığı görülmektedir. İlde üretilen organik ürünlerin çeşitliliği incelendiğinde; ilk sırayı 2.032.04 ton ile narın aldığı, bunu 476 ton ile bademin izlediği, en düşük üretimin ise 0.20 'şer ton ile incir ve kestanede gerçekleştirildiği görülmektedir (Şekil 3) [22].

Doğal toplama alanlarında kekik, adaçayı, dă̆ çayı, fesleğen, defne, mersin, hayıt, biberiye, ıhlamur, ardıç, keçiboynuzu, ısırgan otu, lavanta, papatya, kimyon, nane, funda, yabani elma, armut, erik ve karahan gibi bitkiler gerekli izinler alındıktan sonra toplanarak işlenmektedir. Tıbbi ve aromatik bitkilerden biberiye, kekik, ebegümeci, adaçayı gibi ürünler organik olarak üretilmektedir [16].

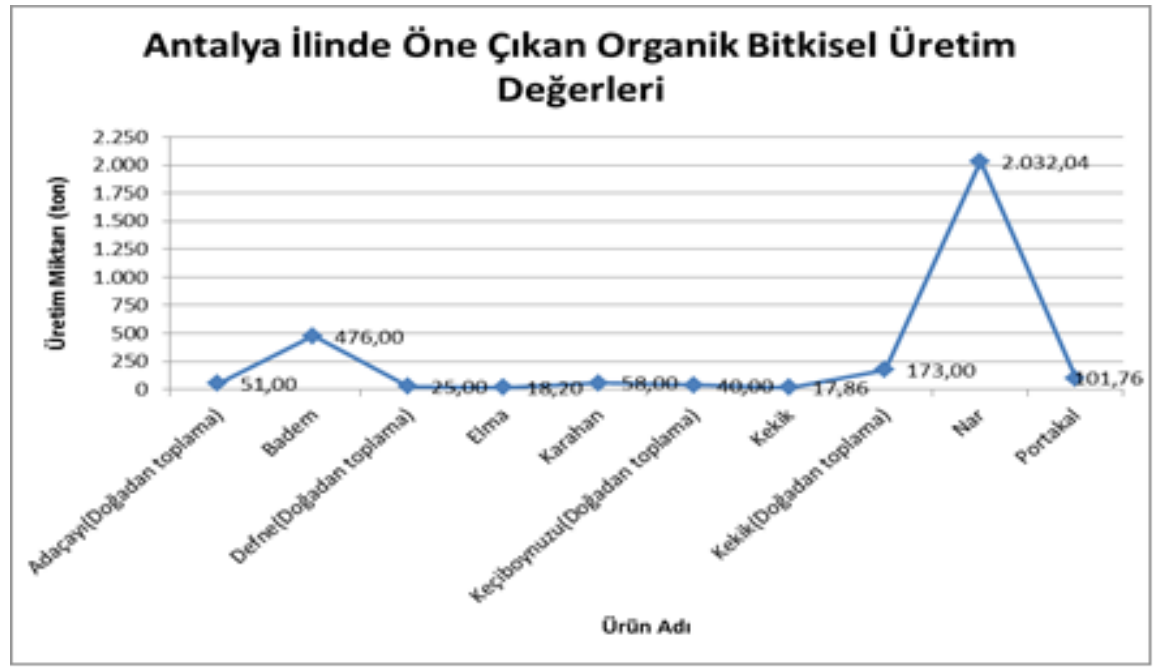

Şekil 3. Antalya ilinde üretilen bazı organik bitkisel ürünler

Ayrıca Antalya'da geçiş sürecinde olan 1.444.60 ton ürün bulunmaktadır. Geçiş sürecinde olan ürünlerden 1.292.78 ton ile portakal ilk sırada yer almaktadır. Portakalı, 92.28 ton ile nar ve 38.50 ton ile erik izlemektedir. En alt sırada ise 0.16 ton ile biber yer almaktadır [22].

Üretilen ürünlerin pazarlanmasına olanak tanıyan \% 100 ekolojik halk pazarı Türkiye'de ilk olarak İstanbul'da ve Antalya'da açılmış [23] fakat Antalya ilindeki pazar tekrar kapanmıştır. Bu durum ildeki organik tarım üretim potansiyelini kısıtlayan bir faktör olarak karşımıza çıkmaktadır.

Antalya ilinde, organik tarımda faaliyet gösteren 2'si kamu, 28'i özel olmak üzere toplam 30 ticari firma bulunmaktadır. $\mathrm{Bu}$ firmalardan sadece 8 tanesi üretim faaliyetinde bulunmaktadır. Bitkisel üretim dişında faaliyet gösteren 16 adet işletmeden 1 adedi ekmek ve ekmek çeşitleri, diğerleri ise organik gübreler, bitkisel menşeili aminoasit içeren organik gübreler, mineral toprak düzenleyicisi, alçıtaşı, solucan kompostu, bionatura ve bitkisel kökenli sıvı hümik asit gibi organik ürünler üretmektedir [24]. 


\subsection{Antalya İl'inde Organik Tarımın Avantaj ve Dezavantajları}

Antalya ilinde organik tarım sektörünün geliştirilmesi ve yaygınlaştırılması aşamalarında karşılaşılabilecek avantaj ve dezavantajlar aşağıda sıralanmıştır.

Avantajlar;

- İlin zengin doğal kaynaklara ve biyoçeşitliliğe sahip olması,

- Organik tarımda ürün çeşitliliğine imkan veren iklim ve toprak yapısının bulunması,

- Özellikle yayla kesimlerinde temiz toprak ve su kaynakları potansiyelinin bulunması,

- Kırsal nüfusta organik tarım açısından önemli bir faktör olan aile içi işgücü varlığı,

- İlde organik tarım ile alakalı kooperatifin bulunması,

- Organik ürünlerin satış değerinin konvansiyonel ürünlere kıyasla yüksek olması,

- İlde eğitim düzeyi ve gelir seviyesi yüksek hedef kitlenin varlığı,

- Organik ürünlerin e-ticaret yöntemiyle aracısız satışlarının yapılabilmesi, bu sayede organik yetiştiricilik yapan üreticilerin doğrudan hedef kitleye ulaşabilmesi,

- İlde bulunan küçük ve orta ölçekli eko-turizm ve agro eko-turizm işletmelerinin deneyimleri paylaşılarak, daha büyük ölçekli işletmelerin kurulabilme imkanının bulunması,

- Sektörün sorunlarının çözümü için üniversitelerle teknik ve bilimsel işbirliğinin sağlanabilme potansiyelinin bulunması, ilde organik tarım konusunda eğitim veren yüksekokulun bulunması,

- Nitelikli işgücü kullanılabilmesi amacıyla, organik tarım teknikeri istihdamı potansiyelinin bulunmasi.

Dezavantajlar

- İlde organik ürünlerin pazarlandığı sabit bir organik pazarın bulunmaması, bununla birlikte ürünlerin pazarlanabileceği yurt içi ve yurtdışı pazarlar hakkında üreticilerin bilgi sahibi olmaması,

- Ürün değerlerinin önemli bir kısmının aracılara ödeniyor olması,

- İlin iklim yapısının seracılığa uygun olması nedeniyle arazilerin büyük bir bölümünde, örtüaltında konvansiyonel üretim yapılıyor olması,

- Organik tarımda kullanılan üretim tekniklerinin, sertifika gibi resmi prosedürlerinin ve devlet desteklerinin üreticiler tarafindan iyi bilinmiyor olması,

- Üretilen organik ürünlerin nakliyesinde ve soğuk zincir ile bozulmadan tüketiciye ulaştırılmasında karşılaşılan problemler ve ekonomik yük,

- Organik tarıma geçiş sürecinde üretim miktarının düşmesinden kaynaklanan gelir düşüklüğünün üretici tarafından tolere edilememesi,

- Hızlı şehirleşmenin arazi varlıklarını tehdit etmesi.Tablo metin içerisinde ortalı olacak şekilde yerleştirilmelidir.

\section{Sonuç ve Öneriler}

İklim özellikleri ve yetiştirilen ürünlerin çeşitliliğinin fazla olması, Antalya ilinin organik bitkisel üretim potansiyelinin yüksek olduğunu göstermektedir. Ancak konvansiyonel yetiştiriciliğin uygulanma kolaylığı ve çiftçinin üretim alışkanlıkları, organik bitkisel üretime yönelimin sınırlı olmasına neden olmaktadır. Organik bitkisel üretiminin yaygınlaştırılması ve konvansiyonel yetiştiricilik ile rekabet edebilir hale gelmesi için öncelikle yapılması gereken çalışmalar; 
1. İl genelinde organik yetiştiriciliğe uygun, kirlenmemiş araziler tespit edilmeli,

2. Geçiş arazisi olabilecek araziler tespit edilerek, arazi sahiplerinin bilinçlenmesi sağlanmalı,

3. Üreticilerin eğitim, teknik ve ekonomik yönden destekleri arttırılmalı,

4. İlde organik tarım alanında faaliyet gösteren ve üretim yapan işletmelerin birçoğu küçük aile işletmeleri veya orta ölçekli işletmelerdir. Bunların çoğunun ürünlerini muhafaza edebilecek depolama olanakları ve soğutmalı araçları da bulunmamakta ve bu durum da üretim miktarının sınırlanmasına yol açmaktadır. Bu durumun çözülmesinde her bir işletmenin bireysel olarak hareket etmesi ekonomik açıdan ağır bir yük getireceğinden, kooperatif ve üretici birliklerinin ortaklaşa hareket etmesi gerekmektedir.

5. Organik tarımda kullanılabilecek bitki koruma ürünleri sınırlı sayıda ve yüksek fiyatlıdır. Bu sebeple üreticilere organik tarımda kullanılabilecek alternatif ev yapımı ilaç yapım teknikleri öğretilmelidir.

6. Coğrafi işaretleme, ürünün kalitesinin korunması ve belli standartta üretimin gerçekleştirilmesine olanak sağlamaktadır. Bu sebeple uygun ürünler için coğrafi işaretleme yoluna gidilmelidir.

7. Agro eko-turizm faaliyetleri desteklenmeli ve mevcut bulunanların tanıtımları yapılmalı, tutundurma yöntemleri olarak fuarlar ve tanıtım günleri düzenlenmelidir.

8. Önemli bir turizm merkezi olan ilin bu potansiyelinin organik tarım alanına aktarılması, yüksek gelirli turistlere yönelik organik menülerin, alışveriş noktalarının oluşturulması gerekmektedir.

9. İlin organik bitkisel üretim miktarının artırılması için öncelikle mevcut konvansiyonel tarım sistemi iyileştirilmeli, sürdürülebilirlik kazanması sağlanmalı ve organik tarıma geçiş kolaylaştırılmalıdır.

\section{Kaynaklar}

[1] Ateş S., Türemiş N. F., "Nevşehir yöresinde tarımsal sürdürülebilirlik yaklaşımı” I. Uluslararası Nevşehir Tarih ve Kültür Sempozyumu,16-19 Kasım, Sempozyum Kitabı, 231s, Nevşehir, 2011.

[2] Yıldırım E., Tarımsal Zararlılarla Mücadele Yöntemleri Ve Kullanılan İlaçlar” Atatürk Üniversitesi Ziraat Fakültesi Ofset Tesisi,325, Erzurum, 2012.

[3] McEwen F. L., Stephenson G. L., "The Use and Significiance of Pesticides in The Environment” John Wiley \& Sons Pub, 538, New York, 1989.

[4] Anonim, “Pesticide”, 2007, http://en.wikipedia.org/wiki/Pesticide/Environmental_effects, Erişim: 09 Aralık 2007.

[5] Anonim 2010. Organik Tarım. T.C. Gıda Tarım ve Hayvancılık Bakanlığı. http://www.tarim.gov.tr/uretim/Organik_Tarim.html, Erişim: 18 Nisan 2013.

[6] İlbaş A. İ., “Organik Tarım İlkeler ve Ulusal Mevzuat”, Eflatun Yayınevi, 267, Ankara. 2009.

[7] FIBL and IFOAM, “The World of Organic Agriculture, Statistics \& Emerging Trends 2014”, FIBL-IFOAM Report, ITC, Geneva, 2014.

[8] Anonim, “Organik Tarımın Geleceği Parlak”, Türkiye Ziraat Odaları Birliği, http://www.tzob.org.tr/Bas\%C4\%B1n- 
das\%C4\%B1/Haberler/ArtMID/470/ArticleID/879/Organik-tar\%C4\%B1m\%C4\%B1ngelece\%C4\%9Fi-parlak, 2013. [Erişim: 13 Haziran 2015].

[9] Baydır F., "Bakanlığımızda dünden bugüne organik tarım”. Türktarım, 156, 26-29, 2004.

[10] Bilen E., Çiçekli Ö., Aksoy U., Altındişli A., “Dünya ve Türkiye’de Organik Tarım” Imak Ofset, 8-37, Ankara, 2012.

[11] Özbilge Z., “An analysis of organic agriculture in Turkey: The current situation and basic constraints” Journal of Central European Agriculture, 8 (2), 213-222, 2007.

[12] Anonim, “Organik Tarım Ulusal Eylem Planı 2013-2016”, T.C. Gıda Tarım ve Hayvancılık Bakanlığı, 2014.

[13] TÜİK, "Bitkisel Üretim İstatistikleri”, http://www.tuik.gov.tr/PreTablo.do?alt_id=1001, 2014, Erişim Tarihi 12.05.2016.

[14] FIBL and IFOAM, “The World of Organic Agriculture, Statistics \& Emerging Trends 2013”, FIBL-IFOAM Report, ITC, Geneva, 2013.

[15] Eryılmaz G. A., Demiryürek K., Emir M., “Avrupa Birliği ve Türkiye’de organik tarım ve gıda ürünlerine karşı tüketici davranışları” Anadolu Tarım Bilimleri Dergisi, 30, 199-206, 2015.

[16] Anonim, “Tıbbi ve Aromatik Bitkiler Sektör Raporu”, 1-16, Anatalya, BAKA, 2012.

[17] TÜİK, "Seçilmiş Göstergelerle Türkiye", Türkiye İstatistik Kurumu, http://www.tuik.gov.tr/ilGostergeleri/index.html, 2013. Erişim Tarihi 05.04.2016

[18] Kaplan M., Sönmez S., Tokmak S., “Antalya-Kumluca yöresi kuyu sularının nitrat içerikleri” Turkish Journal of Agriculture and Forestry, 23, 309-313, 1999.

[19] Özkan B., Akçaöz H. V., Karaman S., Taşçığlu Y., “Antalya ilinde serada sebze üretiminde pestisit kullanımının ekonomik açıdan değerlendirilmesi” Bahçe, 31 (1-2), 9-16, 2002.

[20] Delen N., Durmuşoğlu E., Güncan A., Güngör N., Turgut C., Burçak A., “Türkiye’de Pestisit Kullanımı, Kalıntı ve Organizmalarda Duyarlılık Azalışı Sorunları” Türkiye Ziraat Mühendisliği VI. Teknik Kongresi, Kongre Kitabı, 3-7 Ocak, Ankara, 2005.

[21] Atılgan A., Coşkan A., Saltuk B., Erkan M., “Antalya yöresindeki seralarda kimyasal ve organik gübre kullanım düzeyleri ve olası çevre etkileri” Ekoloji, 15(62), 37-47, 2007.

[22] Anonim, “Organik Tarım İstatistikleri”, T.C. Gıda Tarım ve Hayvancılık Bakanlığı, 2016.

[23] Ataseven Y., Güneş E., “Türkiye'de işlenmiş organik tarım ürünleri üretimi ve ticaretindeki gelişmeler” Uludă Üniversitesi Ziraat Fakültesi Dergisi, 22 (2), 25-33, 2008.

[24] Anonim, “Orman ve Su İşleri Bakanlığı”, Antalya İli Doğa Turizmi Master Planı, Aralık, 2012. 